Pradesh. J Indian Dent Assoc 1982; 54: 367-369

10. Sain B. Incidence of oral \& dental diseases amongst Laotion school children. J Indian Dent Assoc 1979; 51 : 299-302

11. WHO Scientific Group. Tech Rep Ser 621, 1978

2. Miglani DC, Sujeer VN, Chandra R, Raghupathy E. Dental caries, its relationship to saliva and dıet. J Indian Dent Assoc 1970; 42: 219-224

13. Ramachandran K, Rajan BP, Shanmugam S.
Epidemiological studies of dental disorder in Tamil Nadu population. J Indian Dent Assoc $1973 ; 45: 75-70$

14. Tewari A, Chawla HS. A study of prevalence of dental caries in urban area of India. J Indian Dent Assoc 1977; 49 : 231-237

15. Chandra S, Chawla TN. Incidence of dental caries in Lucknow school going children. J Indian Dent Assoc 1979; 51 : 109-110

16. Vaish RP. Prevalence of caries amongst school going tribal children in Ganjam district, Orissa. 1982; $54: 375-377$

\title{
TREATING RHEUMATIC MITRAL STENOSIS WITHOUT SURGERY
}

Rheumatic heart disease remains the most common cardiac disorder in developing countries. Mitral stenosis is a common end result of rheumatic diseases. For surgical repair, most surgeons prefer closed commissurotomy because of its ease, infrequent complications, and lower cost. Some authors however, have recently advocated the use of the open mitral commisurotomy during cardiopulmonary bypass, citing improved valvular function and long-term gradient relief. Recently the development of largediameter balloons mounted on flexible catheter shafts has now made it possible to perform a percutaneous, closed. blind mitral commissurotomy with a blunt dilating instrument.

Percutaneous transcatheter-balloon mitral commissurotomy was attempted in eight children and young adults ( 9 to $23 \mathrm{yr}$ of age) with rheumatic mitral stenosis. The atrial septrum was traversed by needle puncture, and an $8-\mathrm{mm}$ angioplasty balloon was advanced over a guide wire. The atrial septal perforation was then dilated to allow passage of the valvuloplasty balloon catheter $(18$ to $25 \mathrm{~mm}$ ) across the mitral annulus. Inflation of the transmitral balloon decreased the end-diastolic transmitral gradient temporarily in all patients from $21 \cdot 2 \pm 4.0 \mathrm{~mm} \mathrm{Hg}$ (mean \pm S.D.) to $10 \cdot 1 \pm 5 \cdot 5 \mathrm{~mm} \mathrm{Hg}$; $P<0.001)$. The immediate decrease in the gradient was associated with increase in cardiac output (from $3 \cdot 8 \pm 1 \cdot 0$ to $4 \cdot 9 \pm 1 \cdot 3$ litres per minute per square meter of bodysurface area. 